Aus der Klinik für Gefäßchirurgie

(Direktor Univ.-Prof. Dr. med. Michael Jacobs)

\title{
Detecting stent geometry changes after venous recanalization using duplex ultrasound
}

\author{
Von der Medizinischen Fakultät \\ der Rheinisch-Westfälischen Technischen Hochschule Aachen \\ zur Erlangung des akademischen Grades eines Doktors der Medizin genehmigte Dissertation \\ vorgelegt von
}

Mohammad Esmaeil Barbati

aus Babol (Iran)

Berichter: Universitätsprofessor Dr. med. Michael Jacobs

Privatdozent Dr. med. Christian Klink

Tag der mündlichen Prüfung: 12.09.2018

Diese Dissertation ist auf den Internetseiten der Universitätsbibliothek online verfügbar. 
D82 (Diss. RWTH Aachen University, 2018)

https://doi.org/10.1177/0268355518757240

Phlebology: The Journal of Venous Disease

Volume 2018, Article ID 0268355518757240, 9 pages

Copyright@2018 Mohammad Esmaeil Barbati 
Detecting stent geometry changes

\author{
Mohammad E Barbati' $\odot$, Alexander Gombert', \\ Irwin Toonder ${ }^{2}$, Timme MAJ van Vuuren ${ }^{2}$, Karina Schleimer', \\ Jochen Grommes', Cees HA Wittens ${ }^{1,2}$ and Houman Jalaie ${ }^{1,2}$
}

\begin{abstract}
Background: Patients with post-thrombotic syndrome due to chronic venous obstruction and resistant to conservative management can benefit from endovenous revascularization. The current study investigated the usefulness of duplex ultrasound in monitoring the stent changes over the time.

Method: All duplex ultrasound images of treated patients were reviewed retrospectively. The stent diameter and area during the follow-up visits have been analyzed.

Result: A total of 210 stents were placed in 137 limbs. Duplex ultrasound findings showed a decrease in area of stent in all patients (mean: $0.69 \mathrm{~cm}^{2}$ ). Reduction of stent area over the time was a predictor of stent patency (odds ratio: 0.910 ; confidence interval: 0.832-0.997).

Conclusion: Duplex ultrasound has sufficient accuracy in detection of stent changes and its patency. There is a discrepancy between diameter of the stent lumen in vitro and after deployment in all patients. Stent occlusion is related to reduction of stent lumen over the time rather than the percent of the stenosis.
\end{abstract}

\title{
Keywords
}

Venous recanalization, post-thrombotic syndrome, stent geometry, stent patency, ultrasound-color Doppler

\section{Introduction}

Thrombotic or non-thrombotic obstruction of the deep venous system in combination with reflux due to valve incompetence, can initiate a cascade of pathologic processes leading to venous hypertension. ${ }^{1,2}$ Due to the impediment of venous flow, a wide range of clinical symptoms, known as the post-thrombotic syndrome (PTS), can develop. Signs can vary from swelling to non-healing venous ulcer and symptoms can vary from feeling of heaviness in leg to disabling venous claudication. ${ }^{3,4}$

Treatment of patients with PTS is primarily based on conservative management aiming to relieve the symptoms of the disease. ${ }^{5,6}$ Although PTS is not a life-threatening condition, it has a considerable negative effect on the quality of life and can cause significant disability. ${ }^{7,8}$ About $5 \%-10 \%$ of patients with PTS are resistant to the conventional treatment. In these cases, an individualized treatment strategy should be made to relieve the clinical symptoms of PTS. ${ }^{3,9}$

These symptoms may decrease with an endovascular intervention or open surgery by reestablishing the venous drainage pattern. Endovenous revascularization has been performed more frequent with higher success rate as before due to introduction of new imaging modalities, improved recanalization techniques and newly developed dedicated venous stents. Satisfactory clinical results (i.e. decreased pain, swelling and venous claudication, better ulcer healing, and improved Venous Disability Score) are reported after venous angioplasty with stent placement. This technique has already replaced bypass surgery and became the technique of preference for the treatment of acute or chronic iliofemoral obstructive diseases. ${ }^{10,11}$

\footnotetext{
'Department of Vascular Surgery, University Hospital Aachen, Aachen, Germany

${ }^{2}$ Department of Vascular Surgery, Maastricht University Medical Centre, Maastricht, The Netherlands

Corresponding author:

Mohammad E Barbati, University Hospital Aachen, Pauwelsstr. 30, Aachen 52074, Germany.

Email: mbarbati@ukaachen.de
} 
Since stent-related problems occur mainly in the early beginning of the post intervention period, it is crucial to perform close follow-ups at regular intervals to monitor the patency of stents. When used in experienced hands, this can be performed by duplex ultrasound (DUS). Stent geometry, based on duplex findings and clinical evaluation assessment during follow-up controls are useful to determine the need for further intervention to maintain the patency of the stented tract. ${ }^{12}$

The aim of the current study is to investigate the efficiency of DUS in evaluating the stent geometry and early diagnosis of stent stenosis after venous angioplasty and stenting.

\section{Material and methods}

We retrospectively assessed all prospectively recorded data of patients treated by venous angioplasty and stenting from June 2012 to December 2016. All available medical records were reviewed and data on patient demographics, possible deep venous thrombosis (DVT) risk factors, clinical history, comorbidities, and identified prothrombotic conditions (panel including antithrombin, proteins $\mathrm{C}$ and $\mathrm{S}$ levels, anticardiolipin antibodies, and factor $\mathrm{V}$ Leiden) as well as treatment and clinical follow-up were collected.

Exclusion criteria for treatment were peripheral arterial disease, pregnancy, age under 18 years, life expectancy less than one year, and contraindication for therapeutic anticoagulation. Of all analyzed patients, $47(38.8 \%)$ men and $74(61.2 \%)$ women with mean age of 40.6 years (SD: 14.5) were included. A total of 121 patients (137 limbs) with acute or chronic, occlusive or non-occlusive iliofemoral disease who had venous angioplasty and stenting were included in this study.
All patients had preoperative DUS to identify the existence and also the extend of deep venous pathology. Additionally, magnetic resonance venography (MRV) or computed tomography venography (CTV) was performed to assess the extent of disease in the iliocaval and femoral segment and exclude extravascular compression causing obstruction. As a routine follow-up procedure after venous stenting in our center, DUS was performed to evaluate the iliofemoral tract up to infrarenal inferior vena cava (IVC). Two experienced sonographers performed all examinations. The DUS was performed using Philips iU22 ultrasound system (Philips Healthcare, Best, the Netherlands) and 5-10 MHz curved Transducer with a venous preset. All available gray-scale, color/power DUS images were reviewed retrospectively. To have a more precise evaluation of the stent geometry, we used DUS to measure the stent morphology as well as luminal area of the stent in different parts of the stented tract. Proximal, distal, and middle part of the stent, May-Thurner point, stent segment under the inguinal ligament and overlapping zone in cases with more than one stent were the points of interest. We also used the measured stent area and the minimum diameter at the point of maximum compression according to DUS findings before discharge and at the last follow-up just before re-intervention (Figures 1 and 2). The degree of compression was measured with ellipse and calculated as

\section{nominal area of stent $\left(\mathrm{cm}^{2}\right)-$ measured area of stent $\left(\mathrm{cm}^{2}\right) \times 100(\%)$}

The in vitro nominal stent diameter is the diameter provided by the stent manufacturer. The nominal stent area was calculated according to the formula: area $=3.14 \times(\text { diameter } / 2)^{2}$. In patients with patent

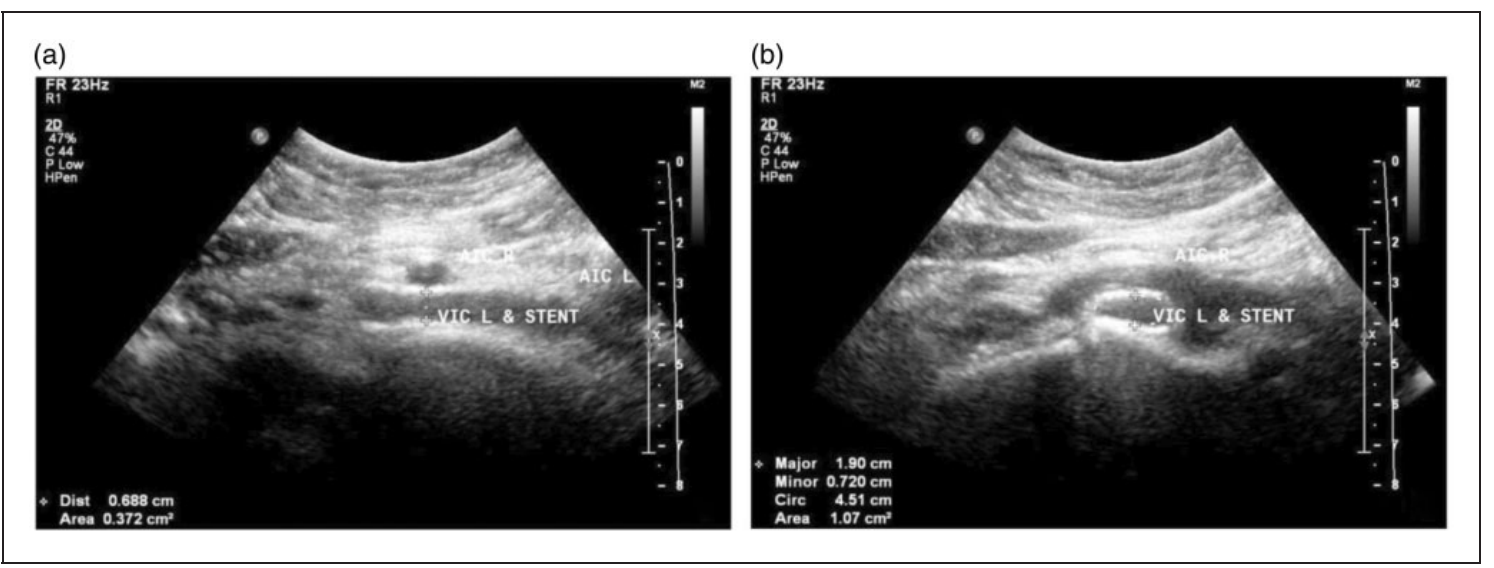

Figure I. Longitudinal (a) and transvers (b) view of ultrasound images in a patient with May-Thurner syndrome treated using a stent with a diameter of $16 \mathrm{~mm}$. External compression due to overriding right common iliac artery results a decrease in intraluminal area (measured: $1.07 \mathrm{~cm}^{2}$, expected: $2.01 \mathrm{~cm}^{2}$ ). 


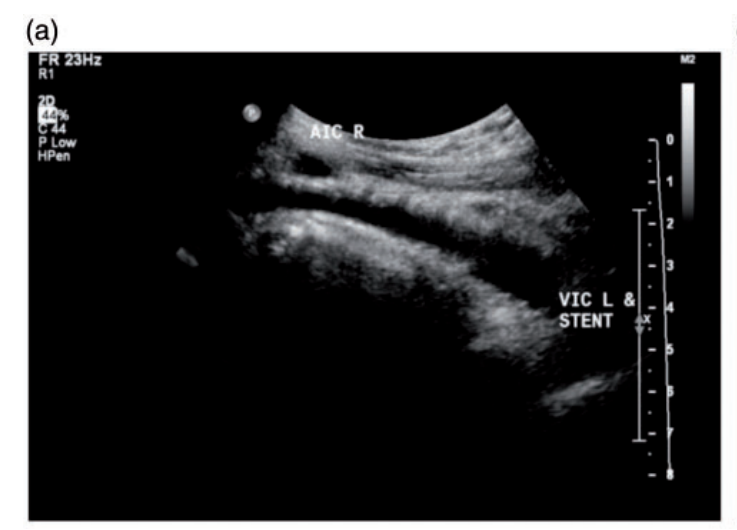

(b)

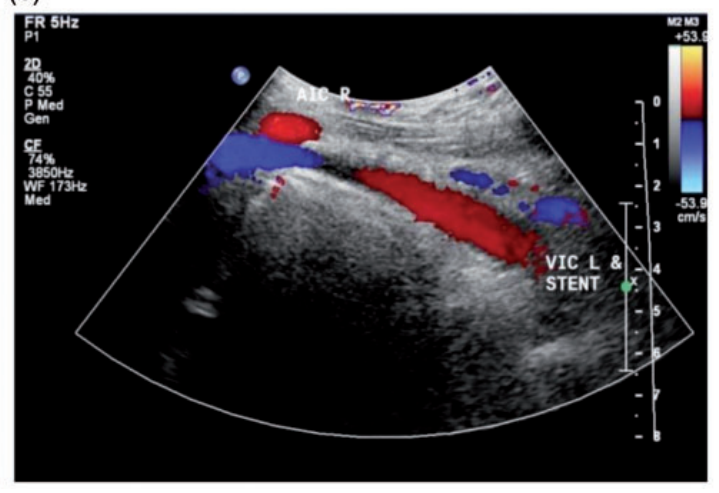

Figure 2. Longitudinal ultrasound images of the stent in common iliac vein. Sufficient stenting of the May-Thurner point with proper stent coverage (a); corresponding color Doppler interrogation demonstrating patency (b).

stents without an additional intervention, the last follow-up data were used. In cases with more than one documented value of the same stent area, a mean of those was used. Patients were divided into three groups according to the onset of DVT and the extent of the venous pathology. The first group consisted of patients with chronic non-thrombotic or post-thrombotic changes without involvement of the femoral confluence $(\mathrm{G} 1, \mathrm{n}=48,39.7 \%)$. Patients with extension of the chronic post-thrombotic changes below the femoral confluence covering the ostium of deep femoral vein, in whom an endophlebectomy with insertion of arteriovenous fistula (AVF) was necessary were assorted in the second group $(\mathrm{G} 2, \mathrm{n}=46,38.0 \%)$. Patients with an acute DVT were established in the third group (G3, $\mathrm{n}=27,22.3 \%$ ).

All patients with an acute DVT had ultrasoundaccelerated catheter-directed lysis using the EKOS catheter (EKOS Corporation, Bothell, Washington, USA) prior to stenting. The operation techniques regarding catheter-directed lysis, percutaneous recanalization, and stenting, as well as endophlebectomy of common femoral vein with creation of AVF have been described in detail elsewhere. ${ }^{13,14}$

The post procedural care consisted of thigh high compression stockings, early mobilization, and evaluation of the stent patency with DUS before discharge. All patients were also prescribed knee high compression stockings (class II) and at least 6 months of therapeutic oral anticoagulation. Clinical follow-up assessments were planned, with the performing of a DUS, at 2 weeks, 3 months, 6 months, and yearly thereafter. Subjective changes in symptoms, stent patency and the measured diameter and area of the stent lumen at the point of maximal compression were documented at each follow-up moment.

\section{Statistical data}

Continuous data are presented as median with range or mean $\pm \mathrm{SD}$, unless otherwise indicated. Comparisons among the groups were performed using a Student's t test for continuous variables with normal distribution. In categorical variables, depending on expected frequency, either Chi-square test or Fisher's exact test were performed. The Cox regression model was used for identification of variables associated with stent failure. Variables that reached statistical significance $(p$-value $<0.10)$ in univariate analysis were incorporated as covariates into the multivariate analysis. Loss of primary patency was defined as stent occlusion or an additional procedure to prevent occlusion. More than 50\% in stent stenosis along with lack of clinical improvement were considered as an indication for re-intervention. Loss of assisted primary patency was defined as occlusion of the treated tract after additional interventions and loss of secondary patency defined as occlusion after initially successfully treated re-occlusion. A Kaplan-Meier survival analysis was used to calculate the patency rates. Standard error of the mean (SEM) values of $>10 \%$ were discarded as being unreliable and are not reported. A $p$-value of $<0.05$ was considered statistically significant. All statistical analyses were performed using IBM SPSS software Version 20 (SPSS Inc, Chicago, IL). Graphs were created using GraphPad Prism version 6.00 for windows (GraphPad Software, San Diego California USA).

\section{Result}

This study included 121 patients, of whom $16(13.2 \%)$ had bilateral treatment of the femoroiliocaval venous tract. The patient characteristics are listed in Table 1. 
Table I. Patient characteristics.

\begin{tabular}{|c|c|c|c|c|c|}
\hline Characteristic & Total $(n=12 \mid)$ & GI $(n=48)$ & $\mathrm{G} 2(\mathrm{n}=46)$ & $\mathrm{G} 3(n=27)$ & $\rho$ \\
\hline Gender & & & & & 0.086 \\
\hline Male, n (\%) & 47 (38.8) & $17(35.4)$ & $22(47.8)$ & $8(29.6)$ & \\
\hline Female, n (\%) & $74(6 \mid .2)$ & $31(64.6)$ & $24(52.2)$ & $19(70.4)$ & \\
\hline Age (years), mean $\pm S D$ & $40.6 \pm 14.5$ & $43.3 \pm 14.9$ & $41.3 \pm 12.8$ & $37.7 \pm 15.5$ & 0.032 \\
\hline BMI $\left(\mathrm{kg} / \mathrm{m}^{2}\right)$, mean $\pm \mathrm{SD}$ & $27.1 \pm 4.0$ & $27.7 \pm 4.2$ & $27.0 \pm 3.8$ & $25.5 \pm 3.8$ & 0.229 \\
\hline Side of pathology & & & & & 0.589 \\
\hline Left, n (\%) & $82(67.8)$ & 35 (72.9) & $28(60.8)$ & $19(70.3)$ & \\
\hline Right, n (\%) & $23(19.0)$ & $9(18.75)$ & $9(19.5)$ & $5(18.5)$ & \\
\hline Both sides, n (\%) & $16(13.2)$ & $4(8.3)$ & $9(19.5)$ & $3(I I . I)$ & \\
\hline
\end{tabular}

GI: post-thrombotic involvement of iliocaval tract + May-Thurner syndrome; G2: GI + involvement of femoral confluence (endophlebectomy + insertion of AVF); G3: deep vein thrombosis (lysis before stenting); BMI: body mass index; AVF: arteriovenous fistula.

A total of 210 stents were placed in 137 limbs (mean: 1.5 per limb). Of all used stents, $181(86.2 \%)$ were dedicated venous stents and $29(13.8 \%)$ non-dedicated venous stents. In 61 limbs one stent was implanted, in 55 limbs two stents and in 14 limbs more than two stents were needed to cover the pathologic area. The mean length of stented area was $168.3 \pm 71.2 \mathrm{~mm}$ and the mean duration of the intervention was $242 \pm 166.6 \mathrm{~min}$ (including the patients with an endophlebectomy) (Table 2). Whenever two or more stents were deployed, the stents were overlapped by at least $1 \mathrm{~cm}$ to ensure adequate stent coverage of the diseased vein. The endovascular and surgical procedures were performed without perioperative or postoperative (<30 days) mortality. There were no major bleeding, cardiac, pulmonary, or renal 30-day complications.

Review of these recordings in first follow-up after endovenous revascularization showed a decrease in area of stent in all patients (mean, range in $\mathrm{cm}^{2} ; 0.69$, $0.06 \mathrm{~cm}^{2}-1.65 \mathrm{~cm}^{2}$ ) comparing to the nominal stent area (Figure 3). The mean percentage decrease of the stent area before the end of the primary patency or until the last follow-up was $36.52 \%$ (SD: $18.13 \%$ ) (Table 2).

In the univariate analysis, the predictors of stent failure included the duration of the operation, length of stented tract and reduction of stent area over the time. In the multivariate analysis, the only significant independent predictor of stent occlusion was the reduction of stent area (odds ratio (OR), 0.910; 95\% confidence interval (CI), 0.832-0.997) (Table 3).

During a median follow-up of 17 months (range: 1-65), primary patency, assisted primary patency, and secondary patency of all patients were $60.3 \%, 76.2 \%$, and $87.3 \%$, respectively (Figure 4).

\section{Discussion}

DUS is a well-established imaging method in diagnosing venous pathology as well as assessing its etiology and extension. Moreover, it is a cost effective imaging method through posttreatment evaluations to identify stent stenosis or occlusion. ${ }^{12,15,16}$ It should be mentioned that the optimal assessment of in-stent changes would be to use intravascular ultrasound (IVUS) to measure wall thickness, total area of stenosis, and any vessel remodeling that may have occurred. ${ }^{11,12,26}$ However, cost and logistics prevents regular use of IVUS as a diagnostic tool in every follow-up controls. For the same reason, conventional venography is a suitable option mostly in patients, in whom an additional intervention is planned and not just as a screening test. In addition, conventional venography is a two-dimensional projection imaging without opacification of the nearby organs.

Alternatively, MRV could be used but is not able to reliably visualize the lumen of metallic stents due to susceptibility artifacts and radiofrequency shielding of metallic stents. ${ }^{17-19}$ Even nitinol stents are not artifact free on MRV images. ${ }^{20}$ Subsequently, CTV remains as the gold standard with a high diagnostic accuracy to evaluate the stent geometry. It has the advantage of providing the three-dimensional images at any desired viewing angle and quality of assessment does not depend on the skill of the examiner. ${ }^{21,22}$ However, It is obvious that CTV does not provide hemodynamic information and benefits of CTV have to be interpreted in the light of the radiation dose and cost-effectiveness of the technique.

In the present study, we performed a comprehensive analysis of stent specification and geometry using DUS images in order to investigate its capability and efficacy in early detection of stent changes to predict the stent outcome.

Reviewing the calculated diameter and measured luminal area of the stent at the first follow-up showed that there was a discrepancy between the measured area of the stent in vivo and its nominal size in vitro (mean, range; $0.69,0.06-1.65)$. According to this finding, 
Table 2. Treatment aspects.

\begin{tabular}{|c|c|c|}
\hline Duration of the operation (min) & Mean \pm SD & $242 \pm 166.6$ \\
\hline \multicolumn{3}{|l|}{ Name of stent } \\
\hline Sinus venous $\left(v^{*}\right)$ & n (\%) & $13 \mid(62.3)$ \\
\hline Sinus $X L(v)$ & n (\%) & $40(19.1)$ \\
\hline Sinus repo $\left(\mathrm{a}^{* *}\right)$ & n (\%) & 25 (1I.9) \\
\hline Sinus flex $(v)$ & n (\%) & $5(2.3)$ \\
\hline Veniti (v) & n (\%) & $4(1.9)$ \\
\hline Andra (a) & n (\%) & $3(1.5)$ \\
\hline Advanta (a) & n (\%) & I (0.5) \\
\hline Sinus obliquus (v) & n (\%) & I $(0.5)$ \\
\hline \multicolumn{3}{|l|}{ Type of stent } \\
\hline Venous stent & n (\%) & |8| (86.2) \\
\hline Arterial stent & n (\%) & $29(13.8)$ \\
\hline \multicolumn{3}{|l|}{ Number of stents per limb } \\
\hline & $0, \mathrm{n}(\%)$ & $7,(5.1)$ \\
\hline & I, n (\%) & $61,(44.6)$ \\
\hline & $2, \mathrm{n}(\%)$ & $55,(40.1)$ \\
\hline & $>2, \mathrm{n}(\%)$ & $14,(10.2)$ \\
\hline \multicolumn{3}{|l|}{ Stented vein segments } \\
\hline IVC & n (\%) & $29(13.8)$ \\
\hline LCIV & n (\%) & $45(21.4)$ \\
\hline LCIV + LEIV & n (\%) & $46(21.9)$ \\
\hline $\mathrm{RCIV}$ & n (\%) & $18(8.6)$ \\
\hline RCIV + REIV & n (\%) & $13(6.2)$ \\
\hline LEIV & n (\%) & $5(2.4)$ \\
\hline LEIV + LCFV & $\mathrm{n}(\%)$ & $33(15.7)$ \\
\hline REIV & n (\%) & $2(0.9)$ \\
\hline $\mathrm{REIV}+\mathrm{RCFV}$ & n (\%) & $15(7.1)$ \\
\hline LCFV & n (\%) & $3(1.5)$ \\
\hline RCFV & $\mathrm{n}(\%)$ & $\mathrm{I}(0.5)$ \\
\hline Length of stented area $(\mathrm{mm})$ & mean $\pm S D$ & $168.3 \pm 71.2$ \\
\hline Follow-up (month) & Median, (range) & $24.50,(1-65)$ \\
\hline Decrease in stent area $\left(\mathrm{cm}^{2}\right)$ at first follow-up (after 2 weeks) & mean $\pm \mathrm{SD}$, (range) & $0.69 \pm 0.42(0.06-1.65)$ \\
\hline Reduction of stent area over the time (\%) & mean $\pm \mathrm{SD}$, (range) & $36.52 \pm 18.13(3.90-83.12)$ \\
\hline
\end{tabular}

$\mathrm{V}^{*}$ : venous dedicated stent; $\mathrm{a}^{* *}$ : arterial stent; IVC: inferior vena cava; LCIV: left common iliac vein; RCIV: right common iliac vein; LEIV: left external iliac vein; REIV: right external iliac vein; LCFV: left common femoral vein; RCFV: right common femoral vein.

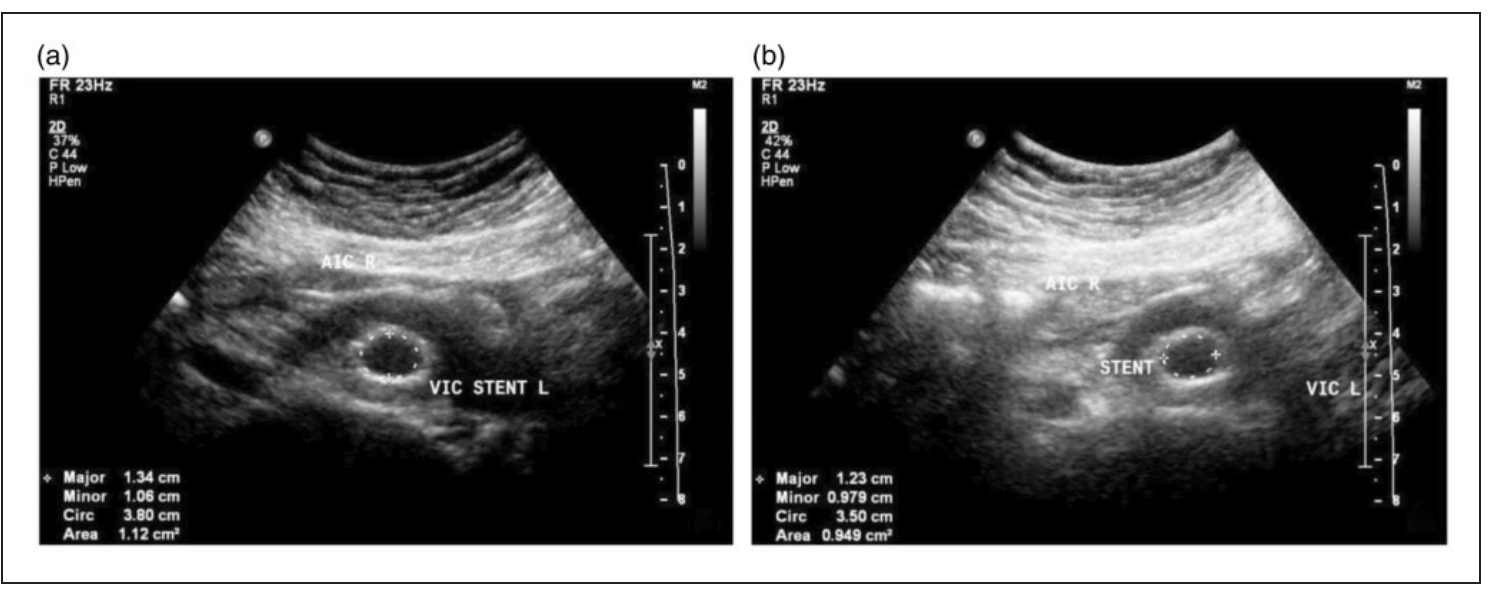

Figure 3. Cross-sectional view of the stent at May-Thurner point before discharge (a) and 6 months after discharge (b) in the same patient demonstrating the reduction of stent area after 6 months $\left(\sim 0.17 \mathrm{I} \mathrm{cm}{ }^{2}\right)$. 
Table 3. Regression analysis of probable factors influencing the patency.

\begin{tabular}{|c|c|c|c|c|c|c|}
\hline \multirow[b]{2}{*}{ Variable } & \multicolumn{3}{|c|}{ Univariate analysis } & \multicolumn{3}{|c|}{ Multivariate analysis } \\
\hline & OR & $95 \% \mathrm{Cl}$ & $p$-value & OR & $95 \% \mathrm{Cl}$ & $p$-value \\
\hline Sex & 0.949 & $0.467-1.931$ & 0.886 & 1.490 & $0.060-36.820$ & 0.808 \\
\hline Age & 0.985 & $0.961-1.009$ & 0.222 & 0.966 & $0.864-1.079$ & 0.540 \\
\hline BMI & 0.950 & $0.866-1.043$ & 0.278 & 0.917 & $0.617-1.368$ & $0.67 \mid$ \\
\hline Duration of the operation & 1.004 & $1.002-1.007$ & 0.001 & 1.009 & $0.997-1.020$ & 0.149 \\
\hline Side of involvement & 0.722 & $0.204-2.55 \mathrm{I}$ & 0.765 & 0.303 & $0.013-6.942$ & 0.455 \\
\hline Type of stent & 1.210 & $0.537-2.729$ & 0.656 & 0.000 & 0.000 & - \\
\hline Length of stented tract & 1.006 & $1.001-1.010$ & 0.015 & 1.015 & $0.995-1.035$ & 0.132 \\
\hline Reduction of stent area & 0.959 & $0.923-0.997$ & 0.023 & 0.910 & $0.832-0.997$ & 0.042 \\
\hline
\end{tabular}

Chi-square: 20.93, degrees of freedom: II, p-value: 0.034 .

BMI: body mass index.

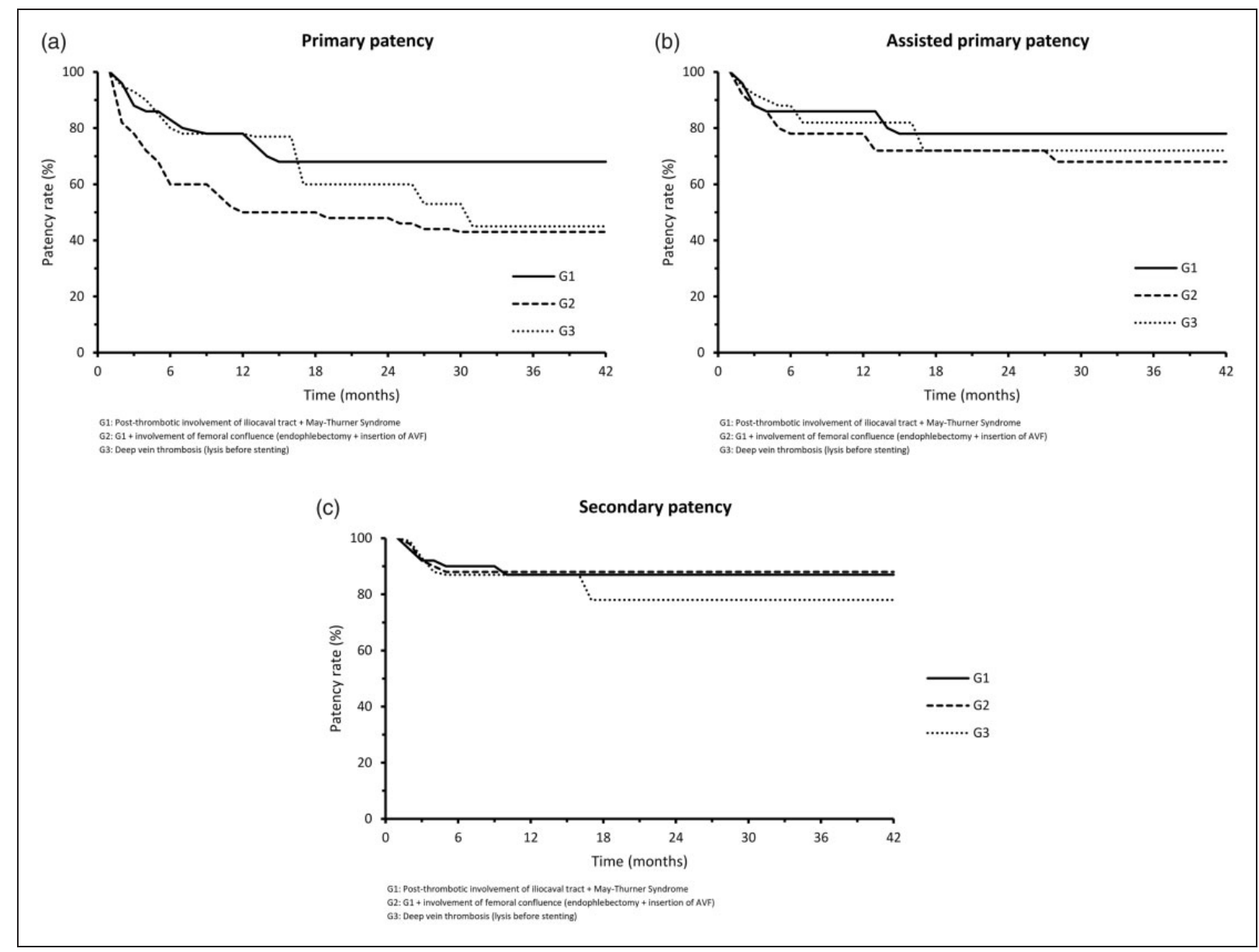

Figure 4. Cumulative primary (a), assisted primary (b), and secondary patency (c) rates after iliofemoral stenting (all standard errors of the mean $<10 \%)$.

despite ballooning before and after stenting, the stents never reached its nominal size after deployment. It reveals the high compression force of adjacent organs as well as constricting tension of intraluminal fibrosis in diseased veins and its walls. It also emphasizes the role and necessity of high radial resistive forces in venous stents to avoid collapsing the vein walls. One solution to minimize this issue is to dilate the vein always before 
stent deployment to help optimal positioning of stents and prevent the recoiling phenomenon to hamper the stent expansion. Some interventionists perform predilatation up to the nominal diameter of the subsequently used stent. ${ }^{12,23}$ Accordingly, it may be safe to perform the predilatation with a larger balloon diameter compared to the intended stent diameter and not to be afraid of probable stent migration.

In the treatment of thrombotic obstruction, adequate inflow and outflow are crucial for long-term patency. The impaired venous drainage causes a poor stent inflow, which has been shown to be an important risk factor for stent occlusion. ${ }^{24}$ In the domain of venous angioplasty, a stent stenosis more than $50 \%$ is commonly accepted as a critical stenosis and should be considered for a re-intervention. ${ }^{11,25-27}$ In this study, the cumulative stent restenosis were $36.52 \%$ at 24 months and the stent occlusion appears to be related to the slowly narrowing of the stent lumen over the time other than other factors (OR: $0.910 ; 95 \% \mathrm{CI}$ : 0.832-0.997; $p$-value: 0.042) (Figure 5). It expresses the necessity of thorough follow-ups, accompanying with measuring the diameter of stent lumen using DUS in a timely manner. As the result, preventive reintervention should be considered in patients with clinical symptoms and persisting reduction of stent lumen even before reaching the critic stenosis.

Our findings identified two other factors associated with the patency of the stent: length of stented tract and duration of the operation. Longer stented area is an indicator of considerably more involvement of venous tract. Moreover, in most cases with venous pathology extending below the femoral confluence, an additional endophlebectomy and insertion of AVF were necessary. Consequently, the recanalization in these cases is more complicated and takes more time (Figure 6).

The reported primary, assisted primary, and secondary patency after venous stenting in literature vary from $8 \%$ to $90.4 \%, 55 \%$ to $99 \%$, and $30 \%$ to $100 \%$, respectively. In general, the better patency rates were reported in studies with shorter follow-up periods, patients with acute DVT or those with more cases of May-Thurner syndrome (MTS) in patient's population. Overall, our findings are consistent with other studies of venous recanalization. ${ }^{11,14,27-32}$ The cumulative primary patency, assisted primary patency, and secondary patency in our study were $60.3 \%, 76.2 \%$, and $87.3 \%$, respectively. Restricting the patency rate to subcategories shows that primary patency in patients with involvement of femoral confluence are significantly lower than two other groups. However, assisted primary and secondary patency in all groups were significantly better than primary patency and statistically identical among three groups (Figure 4).

Although we believe that DUS is a good method to evaluate stent geometry and patency, it has some limitations depending on the experience of the sonographer, body habitus, and artifacts hindering the accuracy of measurements. Despite the fact that comparing the stent lumen in the exact same position was not possible during the follow-ups, our findings suggests a significant progress of stenosis in individual cases. It was also unclear from our data how sufficient was the postoperative anticoagulation and thus no conclusion regarding its effects on in-stent thrombosis can be drawn from the present data.

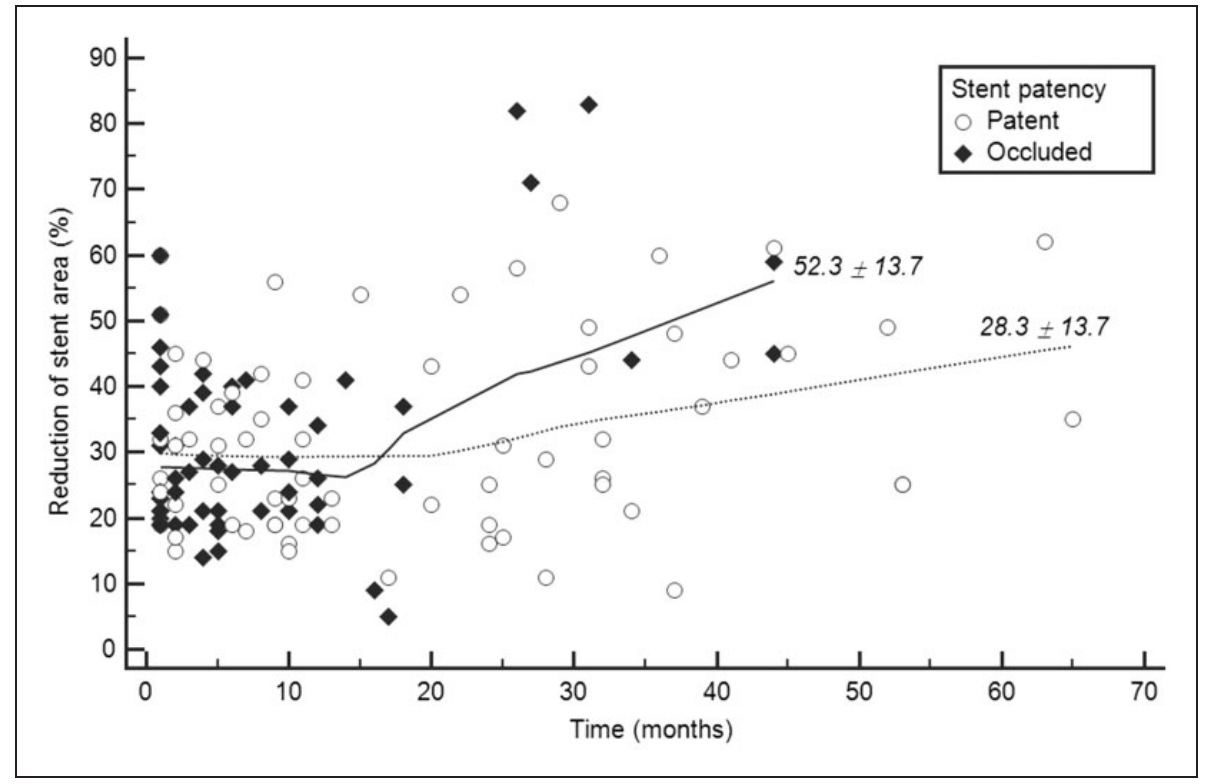

Figure 5. Reduction of stent area over the time and rate of primary patency. 


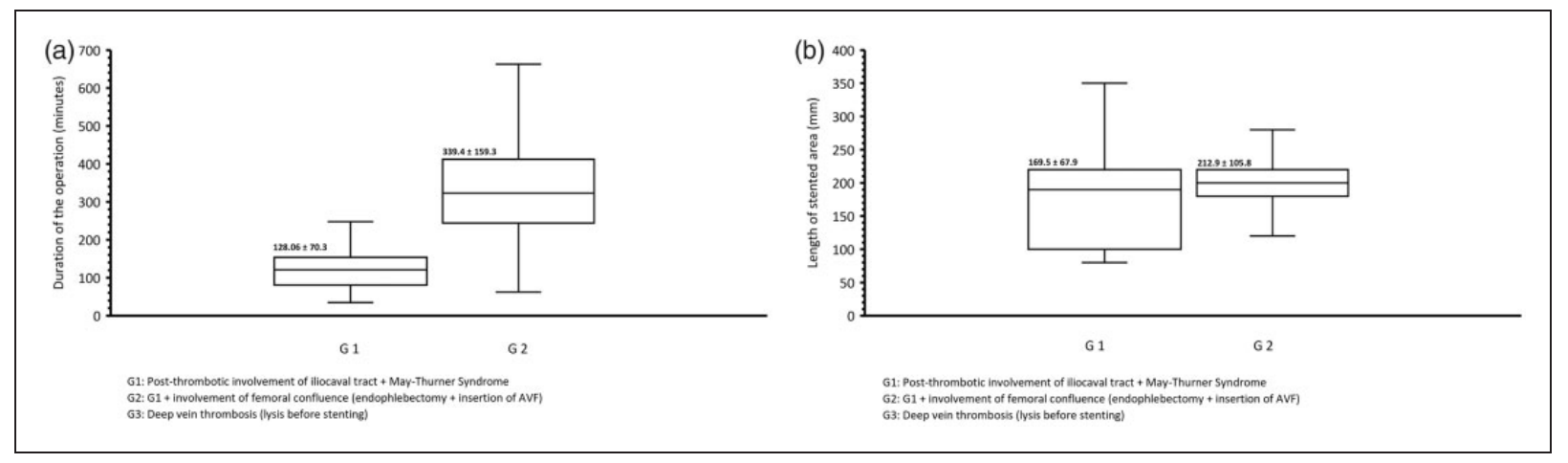

Figure 6. Duration of the operation (a) and length of the stented area (b) in endovenous recanalization. All differences were statistically significant. The box plots represent median (bar), interquartile range (box), and absolute range (whiskers).

\section{Conclusion}

DUS shows a sufficient diagnostic accuracy in the detection of stent changes and its patency. Findings of DUS are suggestive for existing discrepancy between diameters of the stent lumen in vitro and after deployment in all patients. However, stent occlusion appears to be related to reduction of stent lumen over the time rather than the pure percent of the stenosis.

\section{Declaration of Conflicting Interests}

The author(s) declared no potential conflicts of interest with respect to the research, authorship, and/or publication of this article.

\section{Funding}

The author(s) received no financial support for the research, authorship, and/or publication of this article.

\section{Informed Consent}

Not applicable.

\section{Ethical approval}

Under German law, patients treated at a university hospital give automatic consent for their anonymized data to be used in research, unless explicit objections are made.

\section{Guarantor}

Not applicable.

\section{Contributorship}

Not applicable.

\section{Acknowledgments}

Not applicable.

\section{ORCID iD}

Mohammad E Barbati (D) http://orcid.org/0000-0003-07098533

\section{References}

1. Kurstjens RL, de Wolf MA, Konijn HW, et al. Intravenous pressure changes in patients with postthrombotic deep venous obstruction: results using a treadmill stress test. J Thromb Haemost JTH 2016; 14: 1163-1170.

2. Strijkers RH, de Wolf MA and Wittens CH. Risk factors of postthrombotic syndrome before and after deep venous thrombosis treatment. Phlebology 2016; 32: 384-389.

3. Baldwin MJ, Moore HM, Rudarakanchana N, et al. Post-thrombotic syndrome: a clinical review. $J$ Thromb Haemost JTH 2013; 11: 795-805.

4. Kahn SR, Partsch H, Vedantham S, et al. Definition of post-thrombotic syndrome of the leg for use in clinical investigations: a recommendation for standardization. $J$ Thromb Haemost JTH 2009; 7: 879-883.

5. Cohen JM, Akl EA and Kahn SR. Pharmacologic and compression therapies for postthrombotic syndrome: a systematic review of randomized controlled trials. Chest 2012; 141: 308-320.

6. Kahn SR. How I treat postthrombotic syndrome. Blood 2009; 114: 4624-4631.

7. Bergqvist D, Jendteg S, Johansen L, et al. Cost of long-term complications of deep venous thrombosis of the lower extremities: an analysis of a defined patient population in Sweden. Ann Intern Med 1997; 126: 454-457.

8. Kahn SR and Ginsberg JS. Relationship between deep venous thrombosis and the postthrombotic syndrome. Arch Intern Med 2004; 164: 17-26.

9. Kahn SR, Kearon C, Julian JA, et al. Predictors of the post-thrombotic syndrome during long-term treatment of proximal deep vein thrombosis. J Thromb Haemost JTH 2005; 3: 718-723.

10. Hartung O, Lugli M, Nicolini P, et al. Stenting for iliac veins post-thrombotic obstructive lesions: results of a 
multicentric retrospective study. J Vasc Surg 2010; 51: 790.

11. Neglen $\mathrm{P}$, Hollis $\mathrm{KC}$, Olivier $\mathrm{J}$, et al. Stenting of the venous outflow in chronic venous disease: long-term stent-related outcome, clinical, and hemodynamic result. J Vasc Surg 2007; 46: 979-990.

12. Raju S, Tackett P Jr and Neglen P. Reinterventions for nonocclusive iliofemoral venous stent malfunctions. J Vascular Surg 2009; 49: 511-518.

13. Grommes J, Strijkers R, Greiner A, et al. Safety and feasibility of ultrasound-accelerated catheter-directed thrombolysis in deep vein thrombosis. Eur $J$ Vasc Endovasc Surg Off J Eur Soc Vasc Surg 2011; 41: 526-532.

14. Kurstjens RL, de Graaf R, Barbati ME, et al. Arteriovenous fistula geometry in hybrid recanalisation of post-thrombotic venous obstruction. Phlebology 2015; 30: 42-49.

15. Mahnken AH, Thomson $\mathrm{K}$, de Haan M, et al. CIRSE standards of practice guidelines on iliocaval stenting. Cardiovasc Interv Radiol 2014; 37: 889-897.

16. O’Sullivan GJ, Sheehan J, Lohan D, et al. Iliofemoral venous stenting extending into the femoral region: initial clinical experience with the purpose-designed Zilver Vena stent. J Cardiovasc Surg 2013; 54: 255-261.

17. Bartels LW, Smits HF, Bakker CJ, et al. MR imaging of vascular stents: effects of susceptibility, flow, and radiofrequency eddy currents. J Vasc Interv Radiol JVIR 2001; 12: $365-371$.

18. Lenhart M, Volk M, Manke C, et al. Stent appearance at contrast-enhanced MR angiography: in vitro examination with 14 stents. Radiology 2000; 217: 173-178.

19. Maintz D, Kugel H, Schellhammer F, et al. In vitro evaluation of intravascular stent artifacts in threedimensional MR angiography. Investig Radiol 2001; 36: 218-224.

20. Meyer JM, Buecker A, Schuermann K, et al. MR evaluation of stent patency: in vitro test of 22 metallic stents and the possibility of determining their patency by MR angiography. Investig Radiol 2000; 35: 739-746.

21. Sato K, Orihashi K, Takahashi S, et al. Threedimensional CT venography: a diagnostic modality for the preoperative assessment of patients with varicose veins. Ann Vasc Dis 2011; 4: 229-234.

22. Shi W-Y, Wang L-W, Wang S-J, et al. Combined direct and indirect CT venography (combined CTV) in detecting lower extremity deep vein thrombosis. Medicine 2016; 95: e3010.

23. Raju S, McAllister S and Neglen P. Recanalization of totally occluded iliac and adjacent venous segments. J Vasc Surg 2002; 36: 903-911.

24. Jalaie H, Arnoldussen C, Barbati M, et al. What predicts outcome after recanalization of chronic venous obstruction: hemodynamic factors, stent geometry, patient selection, anticoagulation or other factors? Phlebology 2014; 29: 97-103.

25. Knipp BS, Ferguson E, Williams DM, et al. Factors associated with outcome after interventional treatment of symptomatic iliac vein compression syndrome. J Vasc Surg 2007; 46: 743-749.

26. Neglen $P$ and Raju S. In-stent recurrent stenosis in stents placed in the lower extremity venous outflow tract. J Vasc Surg 2004; 39: 181-187.

27. Shaydakov ME, Lurie F, Comerota A, et al. New insight into venous valve physiology: gene expression analysis of human deep veins. J Vasc Surg Venous Lymphat Disord 2016; 4: 138-139.

28. Hartung O. Results of stenting for postthrombotic venous obstructive lesions. Perspect Vasc Surg Endovasc Ther 2011; 23: 255-260.

29. Hartung O, Otero A, Boufi M, et al. Mid-term results of endovascular treatment for symptomatic chronic nonmalignant iliocaval venous occlusive disease. J Vasc Surg 2005; 42: 1138-1144; discussion 44.

30. Neglen P, Tackett TP Jr and Raju S. Venous stenting across the inguinal ligament. J Vasc Surg 2008; 48: 1255-1261.

31. Stuck AK, Kunz S, Baumgartner I, et al. Patency and clinical outcomes of a dedicated, self-expanding, hybrid oblique stent used in the treatment of common iliac vein compression. J Endovasc Ther Off J Int Soc Endovasc Spec 2016; 24: 159-166.

32. Titus JM, Moise MA, Bena J, et al. Iliofemoral stenting for venous occlusive disease. J Vasc Surg 2011; 53: 706-712. 


\section{ACKNOWLEDGEMENTS}

The work presented in this dissertation would not have been possible without my close association with many people. I take this opportunity to extend my sincere gratitude and appreciation to all those who made this dissertation possible.

First and foremost, I would like to express my sincere gratitude to Dr. Houman Jalaie for the patient guidance, encouragement and advice he has provided and also for allowing me to conduct this research under his auspices. I am especially grateful for his confidence and the freedom he gave me to do this work. As my teacher and mentor, he has taught me more than I could ever give him credit for here. He has shown me, by his example, what a good clinician, scientist and person should be.

My special words of thanks should also go to my chief, Professor Michael Jacobs, who has been supportive of my career goals and actively provided me with the protected academic time to pursue those goals.

I would especially like to thank Professor Cees Wittens whose support and guidance helped me in all the time of research and writing of this dissertation. I am extending my thanks to Irwin Toonder for his help in interpreting the images and his feedback on results, which turned my research a success.

I owe my deepest gratitude towards my better half for her eternal support and understanding of my goals and aspirations. Her infallible love and support has always been my strength. Her patience and sacrifice will remain my inspiration throughout my life. Without her help, I would not have been able to complete much of what I have done and become who I am. It would be ungrateful on my part if I thank my loving and supportive wife, Mehrnoush, in these few words.

To my beloved daughter, Mehrshid, I would like to express my thanks for being such a good girl always cheering me up.

Mohammad Esmaeil Barbati 
Erklärung § 5 Abs. 1 zur Datenaufbewahrung

Hiermit erkläre ich, dass die dieser Dissertation zu Grunde liegenden Originaldaten

- $\quad$ bei mir, Mohammad Esmaeil Barbati, Laurentiusstrasse 60, 52072 Aachen, hinterlegt sind. 
Erklärung gemäß § 5 Abs. (1) und (2), und § 11 Abs. (3) 12. der Promotionsordnung ${ }^{1}$

Hiermit erkläre ich, Mohammad Esmaeil Barbati, an Eides statt, dass ich den wesentlichen Anteil an der Publikation:

Barbati M.E., Gombert A., Toonder I., van Vuuren T.M.A.J., Schleimer K., Grommes J., Wittens C.H.A., Jalaie H.: Detecting stent geometry changes after venous recanalization using duplex ultrasound; Phlebology.; 2018

Die Anteile an der Arbeit waren wie folgt:

\begin{tabular}{|c|c|c|c|c|c|c|c|c|c|}
\hline & $\begin{array}{l}\text { Barbati } \\
\text { M.E. }\end{array}$ & Gombert A. & Toonder I. & $\begin{array}{l}\text { van Vuuren } \\
\text { T.M.A.J. }\end{array}$ & Schleimer K. & Grommes J. & Wittens C.H.A. & $\begin{array}{l}\text { Jalaie } \\
\text { H. }\end{array}$ & $\begin{array}{l}\text { Summe } \\
(\%)\end{array}$ \\
\hline Studienüberwachung & 50 & 0 & 0 & 0 & 0 & 10 & 10 & 30 & 100 \\
\hline $\begin{array}{l}\text { Studiendesign/Konze } \\
\text { ption }\end{array}$ & 30 & 10 & 10 & 0 & 0 & 10 & 20 & 20 & 100 \\
\hline Datenerhebung & 60 & 0 & 10 & 30 & 0 & 0 & 0 & 0 & 100 \\
\hline Datenauswertung & 50 & 10 & 0 & 0 & 0 & 10 & 10 & 20 & 100 \\
\hline Statistische Auswert. & 70 & 10 & . & 0 & 0 & 10 & 10 & 0 & 100 \\
\hline $\begin{array}{l}\text { Interpretation der } \\
\text { Datenauswertung }\end{array}$ & 50 & 0 & 10 & 0 & 10 & 0 & 10 & 20 & 100 \\
\hline $\begin{array}{l}\text { Verfassung des } \\
\text { Manuskripts }\end{array}$ & 100 & & & & & & & & 100 \\
\hline $\begin{array}{l}\text { Korrektur des } \\
\text { Manuskripts }\end{array}$ & 20 & 10 & 20 & 0 & 10 & 10 & 10 & 20 & 100 \\
\hline
\end{tabular}

Aus diesem wesentlichen Anteil ergibt sich selbstverständlich die Stellung als Erstautor.

Mohammad Esmaeil Barbati

Als Doktorvater bestätige ich die Angaben von Mohammad Esmaeil Barbati und in Vertretung für die Kooperationspartnern Irwin Toonder, Timme M.A.J. van Vuuren, Prof. Dr. med. Cees Wittens.

Univ.-Prof. Dr. med. Michael Jacobs

Ich schließe mich der Erklärung von Univ.-Prof. Dr. med. Michael Jacobs als Koautor an

Dr. med. Alexander Gombert

Dr. med. Houman Jalaie

Priv.-Doz. Dr. med. Karina Schleimer

$\overline{\text { Priv.-Doz. Dr. med. Jochen Grommes }}$ 


\section{Mohammad Esmaeil Barbati}

\section{8}

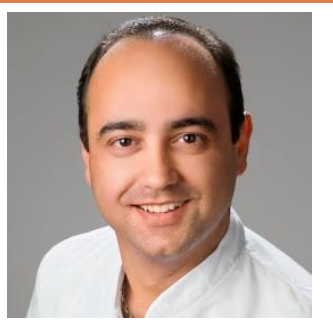

Laurentiusstraße 60

52072 Aachen

Mob: +4915163400675

Tel: +492418035292

E-Mail: mbarbati@ukaachen.de

III science.internal.price
CURRENT POSITION

Clinical fellowship, Department of Vascular and Endovascular

Surgery, University Hospital RWTH Aachen, Germany

\section{W OR K EXPER I E N C E}

Resident, Department of Surgery, St. Antonius Hospital Eschweiler 2014

Resident, Department of Vascular Surgery, Medizinisches Zentrum Städte Region Aachen GmbH Würselen 2013

Resident, Department of Vascular and Endovascular Surgery, University Hospital RWTH Aachen 2012

General Practitioner, Kosar Day Clinic, Tehran 2008 - 2012

Co-Ordinator of Transplant Organs Provision Group, Masih Daneshvari Hospital, Tehran 2004 - 2012

\section{S CIENTIFICPUBLICATIONS}

1. Barbati ME*, Alshabatat AO*, Alzoubi O, Jalaie H, Wittens CH. Role of May-Thurner Syndrome in Recurrent thrombosis after catheter-directed thrombolysis of deep vein thrombosis. Annals of vascular surgery. 2018.

2. Barbati ME, Gombert A, Toonder I, van Vuuren TM, Schleimer K, Grommes J, et al. Defecting stent geometry changes after venous recanalization using duplex ultrasound. Phlebology / Venous Forum of the Royal Society of Medicine. 2018:268355518757240.

3. Schleimer K, Jalaie H, Afify M, Woitok A, Barbati ME, Hoeft K, et al. Sheep models for evaluation of novel patch and prosthesis material in vascular surgery: tips and tricks to avoid possible pitfalls. Acta Veterinaria Scandinavica. 2018,60(1):42.

4. Keschenau PR, Ketting S, Mees B, Barbati ME, Grommes J, Gombert A, et al. Open Thoracic and Thoraco-abdominal Aortic Repair After Prior Endovascular Therapy. European journal of vascular and endovascular surgery : the official journal of the European Society for Vascular Surgery. 2018.

5. Gombert A, van Issum L, Barbati ME, Grommes J, Keszei A, Kotelis D, et al. ExtraThoracic Supra-aortic Bypass Surgery Is Safe in Thoracic Endovascular Aortic Repair and 
Arterial Occlusive Disease Treatment. European journal of vascular and endovascular surgery : the official journal of the European Society for Vascular Surgery. 2018.

6. Gombert A, Gombert R, Barbati ME, Bruners P, Keszei A, Wittens C, et al. Patency rate and quality of life after ultrasound-accelerated catheter-directed thrombolysis for deep vein thrombosis. Phlebology / Venous Forum of the Royal Society of Medicine. 2018;33(4):251-60.

7. Gombert A, Babilon M, Barbati ME, Keszei A, von Trotha KT, Jalaie H, et al. Closed Incision Negative Pressure Therapy Reduces Surgical Site Infections in Vascular Surgery: A Prospective Randomised Trial (AIMS Trial). European journal of vascular and endovascular surgery : the official journal of the European Society for Vascular Surgery. 2018.

8. Schleimer K, Barbati ME, Grommes J, Gombert A, Kotelis D, Kalder J, et al. Restoring of iliofemoral veins after deep vein thrombosis. Phlebologie. 2017,46(46):263-9.

9. Keschenau PR, Kotelis D, Bisschop J, Barbati ME, Grommes J, Mees B, et al. Editor's Choice - Open Thoracic and Thoraco-abdominal Aortic Repair in Patients with Connective Tissue Disease. European journal of vascular and endovascular surgery: the official journal of the European Society for Vascular Surgery. 2017;54(5):588-96.

10. Grommes J, Gombert A, Barbati ME, von Trotha KT, Schleimer K, Jalaie H. [Deep Veins: Hybrid Procedure for Treatment of Iliofemoral Obstruction]. Zentralbl Chir. 2017;142(5):487-91.

11. Gombert A, Barbati ME, Storck M, Kotelis D, Keschenau P, Pape HC, et al. Treatment of blunt thoracic aortic injury in Germany-Assessment of the TraumaRegister DGU(R). PloS one. 2017;12(3):e0171837.

12. Gombert A, Barbati ME, Grommes J, Kurstjens RL, deWolf $M A$, Wittens $C H$, et al. Wound complications after common femoral vein endophlebectomy: Influence on outcome. Phlebology / Venous Forum of the Royal Society of Medicine. 2017:268355517714712.

13. Schleimer K, Barbati ME, Gombert A, Wienert V, Grommes J, Jalaie H. The Treatment of Post-Thrombotic Syndrome. Deutsches Arzteblatt international. 2016;1 13(50):863-70.

14. Jalaie H, Schleimer K, Barbati ME, Gombert A, Grommes J, de Wolf MA, et al. Interventional treatment of postthrombotic syndrome. Gefasschirurgie. 2016;21(Suppl 2):37-44.

15. Gombert A, Barbati ME, Wittens C, Grommes J, Jalaie H. Effect of a new incision management system (PREVENA $(R)$ ) on wound healing after endophlebectomy of the common femoral vein: a case series. Journal of medical case reports. 2016;10:130.

16. Gombert A, Barbati ME, Grommes J, Jalaie H, Schleimer K, Jacobs MJ, et al. Blunt Thoracic Aortic Injury in Case of a 15-Year-Old Boy: Difficulties and Possibilities of the Endovascular Approach. Annals of vascular surgery. 2016;33:228.e15-9.

17. Kurstiens RL, de Graaf R, Barbati ME, de Wolf MA, van Laanen JH, Wittens CH, et al. Arteriovenous fistula geometry in hybrid recanalisation of post-thrombotic venous obstruction. Phlebology / Venous Forum of the Royal Society of Medicine. 2015;30(1 Suppl):42-9.

18. Jalaie H, Arnoldussen C, Barbati ME, Kurstjens R, de Graaf R, Grommes J, et al. What predicts outcome after recanalization of chronic venous obstruction: hemodynamic factors, stent geometry, patient selection, anticoagulation or other factors? Phlebology / Venous Forum of the Royal Society of Medicine. 2014;29(1 suppl):97-103.

19. Noohi S, Azar M, Behzadi AH, Barbati ME, Haghshenas A, Amoozgar B, et al. Comparison of sexual function in females receiving haemodialysis and after renal transplantation. Journal of renal care. 2010;36(4):21 2-7.

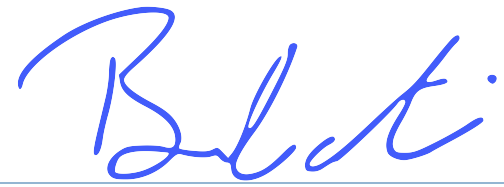

